Journal of Dairy Research

cambridge.org/dar

\section{Invited Review}

Cite this article: Gutiérrez-Reinoso MA, Aponte PM and García-Herreros M (2022). A review of inbreeding depression in dairy cattle: current status, emerging control strategies, and future prospects. Journal of Dairy Research 89, 3-12. https://doi.org/10.1017/ S0022029922000188

Received: 20 May 2021

Revised: 6 October 2021

Accepted: 13 December 2021

First published online: 28 February 2022

\section{Keywords:}

Adaptability; dairy cattle; health; inbreeding depression; linear conformation; production; reproduction; welfare

Author for correspondence:

Manuel García-Herreros,

Email: herrerosgm@gmail.com (c) The Author(s), 2022. Published by Cambridge University Press on behalf of Hannah Dairy Research Foundation

Hannah Dairy Research Foundation

\section{CAMBRIDGE UNIVERSITY PRESS}

\title{
A review of inbreeding depression in dairy cattle: current status, emerging control strategies, and future prospects
}

\author{
Miguel A. Gutiérrez-Reinoso ${ }^{1,2}$, Pedro M. Aponte ${ }^{3,4}$ and Manuel García-Herreros ${ }^{5}$
}

\begin{abstract}
${ }^{1}$ Universidad Técnica de Cotopaxi, Facultad de Ciencias Agropecuarias y Recursos Naturales, Carrera de Medicina Veterinaria (UTC), Latacunga, Ecuador; 'Laboratorio de Biotecnología Animal, Departamento de Ciencia Animal, Facultad de Ciencias Veterinarias, Universidad de Concepción, Chillán (UdeC), Chile; ${ }^{3}$ Universidad San Francisco de Quito (USFQ), Colegio de Ciencias Biológicas y Ambientales (COCIBA), Campus Cumbayá, Quito, Ecuador; ${ }^{4}$ Instituto de Investigaciones en Biomedicina, iBioMed, Universidad San Francisco de Quito (USFQ), Campus Cumbayá, Quito, Ecuador and ${ }^{5}$ Instituto Nacional de Investigação Agrária e Veterinária (INIAV), Santarém, Portugal
\end{abstract}

\begin{abstract}
Dairy cattle breeding has historically focused on relatively small numbers of elite bulls as sires of sons. In recent years, even if generation intervals were reduced and more diverse sires of sons could have been selected, genomic selection has not fundamentally changed the fact that a large number of individuals are being analyzed. However, a relatively small number of elite bulls are still siring those animals. Therefore inbreeding-derived negative consequences in the gene pool have brought concern. The detrimental effects of non-additive genetic changes such as inbreeding depression and dominance have been widely disseminated while seriously affecting bioeconomically important parameters because of an antagonistic relationship between dairy production and reproductive traits. Therefore, the estimation of benefits and limitations of inbreeding and variance of the selection response deserves to be evaluated and discussed to preserve genetic variability, a significant concern in the selection of individuals for reproduction and production. Short-term strategies for genetic merit improvement through modern breeding programs have severely lowered high-producing dairy cattle fertility potential. Since the current selection programs potentially increase long-term costs, genetic diversity has decreased globally as a consequence. Therefore, a greater understanding of the potential that selection programs have for supporting long-term genetic sustainability and genetic diversity among dairy cattle populations should be prioritized in managing farm profitability. The present review provides a broad approach to current inbreeding-derived problems, identifying critical points to be solved and possible alternative strategies to control selection against homozygous haplotypes while maintaining sustained selection pressure. Moreover, this manuscript explores future perspectives, emphasizing theoretical applications and critical points, and strategies to avoid the adverse effects of inbreeding in dairy cattle. Finally, this review provides an overview of challenges that will soon require multidisciplinary approaches to managing dairy cattle populations, intending to combine increases in productive trait phenotypes with improvements in reproductive, health, welfare, linear conformation, and adaptability traits into the foreseeable future.
\end{abstract}

\section{Introduction}

Inbreeding decreases the performance of dairy cattle by directly or indirectly affecting various productive and reproductive parameters (Gutiérrez-Reinoso et al., 2020). During the 1970s, in countries such as the United States, the degree of inbreeding was recorded to be in the order of $3-6 \%$ in the Holstein breed (Young, 1984). This problem occurs because breeding programs in dairy cattle incentivize and reinforce matings between genetically related individuals, driving the phenomenon called inbreeding depression (Baes et al., 2019). Even though estimates of genomic values have received much attention in recent years, estimates of inbreeding depression in dairy cattle are rare in the literature (Maltecca et al., 2020). Several authors suggest a variable influence of genomic selection on the effect of inbreeding (Howard et al., 2017; Baes et al., 2019; Doekes et al., 2019). In dairy cattle, the impact of inbreeding depression in recent generations is projected to drive very adverse effects compared to old inbreeding (distant generations) (Makanjuola et al., 2020). However, inbreeding may exert a detrimental effect only on specific traits (Doekes et al., 2019; Gutierrez-Reinoso et al., 2021).

Implementing genomic evaluations has drastically changed how breeding systems are conducted in dairy cattle breeds (Howard et al., 2017). Traditionally, pedigree-derived data was highly valuable for assessing the genetic diversity of non-genotyped individuals (Sonesson et al., 2012). However, genomics has enabled more precise studies of the proportion of the inbreeding patterns across the genome (Howard et al., 2017; Sell-Kubiak et al., 2018). 
Thus, genomics-based estimates started to be used to manage genetic diversity in animal selection programs, including dairy cattle (Sonesson et al., 2012).

Inbreeding has been described as a cause of the reduced performance of productive and reproductive traits in dairy cattle by increasing the frequency of deleterious or non-deleterious recessive homozygous genotypes leading to the loss of genetic dominance and other non-additive effects (VanRaden, 1992; McParland et al., 2009; Pryce et al., 2014; Dezetter et al., 2015; Gutiérrez-Reinoso et al., 2020). Consequently, inbreeding depression can be reduced by minimizing overall inbreeding and avoiding the production of recessive homozygous offspring (Leroy, 2014; Pryce et al., 2014).

The accumulation of annual genetic gain has gathered momentum for major dairy cattle breeds (Doublet et al., 2019) due to the implementation of genomic selection during the last decades. Still, unfortunately, the annual loss of genetic diversity has increased considerably, reflecting the emergence of recent inbreeding (Makanjuola et al., 2020). Therefore, understanding the impact of genomic selection on genetic diversity and the factors involved in different genetic traits (productive, reproductive, type, health, conformation, and adaptation, among others) as well as inbreeding rates based on genomics and pedigree estimations is critical for the development of dairy cattle selection programs (Pryce et al., 2014; Doublet et al., 2019; Gutierrez-Reinoso et al., 2021).

Despite the evident negative influence of inbreeding on several genetic traits in dairy cattle (McParland et al., 2009; Pryce et al., 2014; Dezetter et al., 2015; Gutiérrez-Reinoso et al., 2020), the mating of genetically related individuals continues to be carried out (Baes et al., 2019). Breeding organizations continue to develop breeding programs involving very close or genetically related genetic lines, intending to fix different traits of interest (Gandini et al., 2014). This issue has led to a vicious circle, negatively impacting genomic and phenotypic traits related to production, reproduction, conformation, health, and adaptability. For example, Holstein bulls show a higher annual genetic variability loss than other dairy breeds (Doublet et al., 2019). To progressively generate understanding in the industry for the need to mitigate the negative inbreeding derived effects in dairy cattle breeds, urgent characterization, and dissemination of information on the extent of inbreeding and inbreeding coefficients of specific bulls are becoming extremely important.

The present review sets out the primary objectives of providing a broader understanding of the importance of genomic analysis and exploring possible applications to mitigate the undesirable effects of inbreeding depression on different traits of production, reproduction, health and welfare, linear conformation and adaptability. We will address topics related to the use and influence of genomic analysis on genotypic traits affected by inbreeding in dairy cattle. This review paper is designed and organized as follows: a brief history of the emergence of the concept of inbreeding/endogamic depression, the impact of the negative effect of inbreeding on production traits, reproduction, animal health-welfare, linear conformation, and adaptability indices in different cattle operation systems, as well as causal and highly predictive genetic variants potentially key to the prediction of other complex traits. Furthermore, we will provide evidence that the control of inbreeding depression should focus on current methodologies applied to genomic selection. Promising new approaches to dairy cattle genomic selection based on genomic analysis show excellent potential to control the genetic gain of genomic traits that influence different aspects of dairy cattle. These tools are essential to improve the prediction of the effects derived from increased homozygosity. However, considerable challenges exist to integrate a genomic analysis model that increases the accuracy of prediction for different genetic traits while at the same time detecting a greater or lesser increase in inbreeding depression. Therefore, monitoring the degree of homozygosity in dairy cattle becomes a critical factor, instrumental for controlling and determining the possible adverse effects derived from it. Consequently, follow-up of the phenomenon of homozygosity must be considered to counteract endogamic effects. This way, we can ensure a sustainable future and profitability during the productive life of dairy cattle across generations.

\section{Inbreeding depression: history, background and current status}

Inbreeding is the probability of two alleles in an individual being identical by descent due to mating-related individuals. The inbreeding rate is a function of the characteristics of the foundation stock as well as limited population sizes in subsequent generations (Possingham et al., 2013). Inbreeding resulting from the mating between animals of standard genetic lines can be associated with a decrease or loss of the biological capacity called inbreeding depression. This concept is advanced by different authors who maintain that high levels of endogamy are undesirable because they diminish genetic diversity and yields of the future generations due to positive or negative influences over different traits (Miglior et al., 2001; Croquet et al., 2006; Doekes et al., 2019; Doublet et al., 2019) (Fig. 1). The first studies to demonstrate the effects of inbreeding depression were conducted in plants and, later, the concept was extrapolated to animal species.

Initially, evaluations of the degree and consequences of inbreeding in dairy cattle breeds were based on estimates of pedigree data. Consequently, predictions of inbreeding coefficients used to be fluctuating and imprecise (Howard et al., 2017). Today, computerized animal selection programs have substantially improved the estimation of traits by reasonably limiting the degree of inbreeding in subsequent generations (Weigel and Lin, 2000). In parallel to these studies, a large number of meta-analyses have been conducted on various livestock species, demonstrating that reproductive traits are more severely depressed than other traits (McParland et al., 2007; Ma et al., 2019). Overall, for every $1 \%$ increase in the degree of inbreeding, an average decrease of $0.137 \%$ of some traits is estimated (Leroy, 2014), including production losses (McParland et al., 2007; Dezetter et al., 2015; Doekes et al., 2019). In other cases, inbreeding depression has been observed to cause yield losses for production traits like for instance -32 to $-41 \mathrm{~kg}$ of $305 \mathrm{ME}$ milk, -1.4 to $-1.7 \mathrm{~kg}$ of $305 \mathrm{ME}$ fat, and -1.1 to $-1.3 \mathrm{~kg}$ of $305 \mathrm{ME}$ protein by percent inbreeding (Dezetter et al., 2015), or reducing fat and protein concentrations by $0.05 \%$ and $0.01 \%$, respectively while somatic cell scores increased by 0.03-0.86 units (McParland et al., 2007; Doekes et al., 2019). (Table 1). Also, due to the effect of inbreeding, $2 \%$ more dystocia, $1 \%$ more stillbirths, $0.7 \%$ more male calves, an increase of calving interval of $8.8 \mathrm{~d}$ and increased age at first parturition of $2.5 \mathrm{~d}$ have been reported (McParland et al., 2007; Ma et al., 2019) (Table 2).

Despite the findings of several studies that suggest inbreeding negatively affects productive and other traits (Rokouei et al., 2010; Dezetter et al., 2015; Howard et al., 2017; Martikainen et al., 2017; Yurchenko et al., 2018; Doublet et al., 2019), other authors 


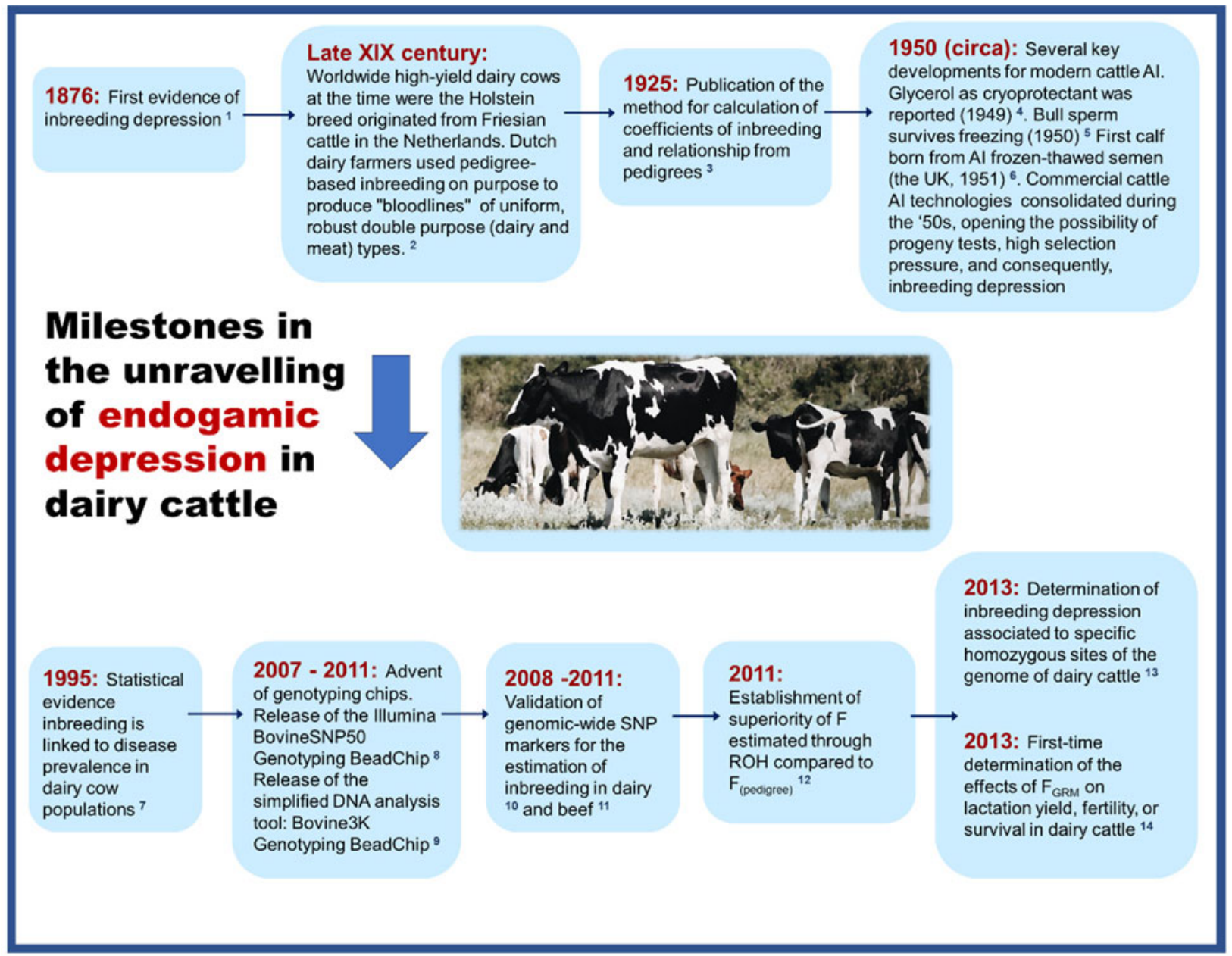

Fig. 1. Milestones in the unraveling of endogamic depression in dairy cattle. Al $=$ artificial insemination; $F_{\text {(pedigree) }}=$ coefficient of inbreeding estimated through pedigree; $\mathrm{ROH}=$ Runs of homozygosity; $F_{\mathrm{GRM}}=$ Inbreeding coefficient based on the genomic relationship matrix. References: (1) (Darwin, 1876); (2) (Theunissen, 2008); (3) (Wright and McPhee, 1925); (4) (Polge and Rowson, 1952); (5) (Bailey, 2017); (6) (Leibo et al., 1994); (7) Miglior et al., 1995); (8) (BovineSNP50 DNA Analysis Kit, 2021); (9) (Data Sheet: DNA Analysis, 2021); (10) (VanRaden et al., 2011); (11) (Hayes and Goddard, 2008); (12) (Keller et al., 2011); (13) (Pryce et al., 2014); (14) (Bjelland et al., 2013).

indicate that inbreeding is unlikely to cause large losses (McParland et al., 2007). Although overdominance and epistasis may contribute to inbreeding depression in dairy cattle, partial dominance is expected to account for the more significant proportion of inbreeding depression. Thus, the degree and timing of inbreeding do not always seem to be negative, considering that recent inbreeding is more detrimental than old inbreeding (Doekes et al., 2019). In dairy breeds such as Holstein and Jersey, these effects would be accompanied by an increased frequency of unfavorable homozygous recessive genotypes (Pryce et al., 2014). Therefore, the estimation of genomic homozygosity seems to be a more accurate tool than the pedigree-based inbreeding coefficient (Kardos et al., 2015; Baes et al., 2019).

There is a consensus that the effect of inbreeding at undesirable levels seriously affecting genetic variability, as well as the performance in generations of dairy cattle (Croquet et al., 2006; Doekes et al., 2019; Doublet et al., 2019; Miglior et al., 2001) is associated to specific genomic regions (Pryce et al., 2014). This implies that inbreeding coefficients vary and are inaccurate when their predictions are based solely on pedigree data (Howard et al., 2017). One summarizing remark from the above studies is that the continuous use of genomic evaluation as a routine method in bovine genetic improvement programs is highly relevant to positively impact the reduction of the degree of inbreeding in the future generations (de Oliveira Seno et al., 2018). However, estimation of genomic homozygosity appears to be a more accurate tool (Kardos et al., 2015; Baes et al., 2019), so linking these two factors (genomics and pedigree) significantly improves the estimation of prediction for the most desirable traits of interest in dairy cattle (Weigel and Lin, 2000).

\section{Inbreeding depression in dairy cattle: production, reproduction, health and welfare, linear conformation and adaptability}

\section{Impact of inbreeding depression on production}

One of the main advantages of bovine genome sequencing is that it has contributed significantly to the analysis and interpretation of the functionality of genes. This advance leads to opportunities to answer the problem of the overuse of existing genetic lines in dairy breeds that has generated an increase in the consanguinity index (Doekes et al., 2019). The reported incidence of inbreeding and, consequently, inbreeding depression is evident in several 
Table 1. Regression coefficients of inbreeding depression for production and conformation for production traits per $1 \%$ increase in inbreeding in dairy cattle (genomics vs. pedigree)

\begin{tabular}{|c|c|c|c|c|}
\hline Parameters & $\begin{array}{l}\text { Means estimates per } \\
\text { every } 1 \% \text { increase in } \\
\text { inbreeding (genomics) }\end{array}$ & References & $\begin{array}{c}\text { Means estimates } \\
\text { per every } 1 \% \\
\text { increase in } \\
\text { inbreeding (pedigree) }\end{array}$ & References \\
\hline \multicolumn{5}{|l|}{ Production } \\
\hline 305-d milk (kg) & -36.30 & Doekes et al. (2019) & -19.68 & Croquet et al. (2006) \\
\hline Somatic cells (CFUs) & 0.86 & Doekes et al. (2019) & 0.52 & Croquet et al. (2006) \\
\hline 305-d Fat (kg) & -2.42 & Doekes et al. (2019) & -0.96 & Croquet et al. (2006) \\
\hline Protein yield (kg) & -1.20 & Bjelland et al. (2013) & -0.69 & Croquet et al. (2006) \\
\hline \multicolumn{5}{|c|}{ Conformation for production } \\
\hline Stature & -0.06 & Bjelland et al. (2013) & -0.24 & Croquet et al. (2006) \\
\hline Body depth & -0.14 & Bjelland et al. (2013) & -0.48 & Croquet et al. (2006) \\
\hline Loin strength & -0.19 & Bjelland et al. (2013) & -0.14 & Croquet et al. (2006) \\
\hline Foot angle & -0.04 & Bjelland et al. (2013) & -0.47 & Croquet et al. (2006) \\
\hline Rear leg rear view & -0.14 & Bjelland et al. (2013) & -0.62 & Croquet et al. (2006) \\
\hline Udder depth & 0.06 & Bjelland et al. (2013) & 0.30 & Croquet et al. (2006) \\
\hline Udder support & 0.04 & Bjelland et al. (2013) & -0.13 & Croquet et al. (2006) \\
\hline Front teat placement & 0.18 & Bjelland et al. (2013) & 0.16 & Croquet et al. (2006) \\
\hline Teat length & -0.13 & Bjelland et al. (2013) & -0.13 & Croquet et al. (2006) \\
\hline Rear udder height & -0.05 & Bjelland et al. (2013) & -0.03 & Croquet et al. (2006) \\
\hline Rear udder width & -0.05 & Bjelland et al. (2013) & -0.28 & Croquet et al. (2006) \\
\hline Rear teat placement & 0.12 & Bjelland et al. (2013) & 0.01 & Croquet et al. (2006) \\
\hline Overall fore udder & -0.02 & Bjelland et al. (2013) & 0.03 & Croquet et al. (2006) \\
\hline Overall dairy trait & -0.03 & Bjelland et al. (2013) & -0.05 & Croquet et al. (2006) \\
\hline
\end{tabular}

Estimates were readjusted as standardized linear regression coefficients.

traits, particularly in production traits (Pryce et al., 2014). Thus, inbreeding generates a substantial effect on milk, fat, and protein derived-traits, and an alteration of the somatic cell count as evaluated through genealogical information of sires and dams of different dairy breeds (Croquet et al., 2007; Rokouei et al., 2010; Bjelland et al., 2013; Dezetter et al., 2015). In another study involving Jersey animals in which different degrees of inbreeding were estimated over time and their relationship with production and genealogical data was quantified, a greater negative presence of inbreeding in animals of early ages and at the beginning of lactation was found (Thompson et al., 2000). Also, in other breeds such as Ayrshire, this time introducing genomic analysis, harmful homozygous recessive alleles have been identified to be responsible for the increase in inbreeding depression affecting production traits in general (Martikainen et al., 2020). When identical haplotypes are inherited from both parents, inbreeding seems to be related to continuous lengths of homozygous genotypes (runs of homozygosity, ROH). These may be formed with deleterious (lethal) recessive alleles and could be associated with inbreeding depression and consequently with a decreased phenotypic performance. In the Ayrshire dairy breed, several ROHs have been reported to adversely affect production and reproductive traits (Martikainen et al., 2020). However, not all ROHs in a region may have negative effects on the trait of interest. Therefore, more efficient control of inbreeding depression could minimize the occurrence of unfavorable haplotypes as homozygous status in breeding programs.

According to Doekes et al. (2019), inbreeding in Dutch Holstein-Friesian cows decreases animal performance traits (inbreeding depression), but inbreeding may not always be detrimental. In the Holstein breed, the effect of the degree of ancestral and current inbreeding ratifies the harmful effects of inbreeding on production traits (McParland et al., 2009). Over time the frequency of deleterious (lethal) alleles decreases due to a selection process called genetic purging, and recent inbreeding may be more harmful than old inbreeding. In both production and reproductive traits, long and short ROHs contributed to inbreeding depression (Doekes et al., 2019).

Genomics has recently emerged as a tool for the evaluation of inbreeding depression. Several genomic studies have detected the continuous increase of inbreeding indexes associated with deleterious homozygous recessive alleles, responsible for the rise of inbreeding depression affecting production traits in several dairy breeds (Croquet et al., 2007; Rokouei et al., 2010; Bjelland et al., 2013; Dezetter et al., 2015; Doekes et al., 2019), such as the Ayrshire (Martikainen et al., 2020), Jersey (Thompson et al., 2000) and Holstein (McParland et al., 2009). Therefore, the implementation of genomic analysis is essential to understand the functionality and potential of some genes to influence productive traits and establish the size of the association of 
Table 2. Regression coefficients of inbreeding depression for reproduction and conformation for ease of calving traits per $1 \%$ increase in inbreeding in dairy cattle (genomics vs. pedigree)

\begin{tabular}{|c|c|c|c|c|}
\hline Parameters & $\begin{array}{l}\text { Means estimates per } \\
\text { every } 1 \% \text { increase in } \\
\text { inbreeding (genomics) }\end{array}$ & References & $\begin{array}{l}\text { Means estimates per } \\
\text { every } 1 \% \text { increase in } \\
\text { inbreeding (pedigree) }\end{array}$ & References \\
\hline \multicolumn{5}{|l|}{ Reproductive } \\
\hline AFS_H (d) & 0.35 & Makanjuola et al. (2020) & 0.44 & Makanjuola et al. (2020) \\
\hline NS_Hc & 0.99 & Makanjuola et al. (2020) & 0.96 & Makanjuola et al. (2020) \\
\hline NRR_Hc & -0.19 & Makanjuola et al. (2020) & -0.01 & Makanjuola et al. (2020) \\
\hline FSTC_H (d) & 0.31 & Makanjuola et al. (2020) & 0.29 & Makanjuola et al. (2020) \\
\hline CTFS_C (d) & 0.02 & Makanjuola et al. (2020) & 0.07 & Makanjuola et al. (2020) \\
\hline NS_Cc & 0.70 & Makanjuola et al. (2020) & 0.45 & Makanjuola et al. (2020) \\
\hline NRR_Cc & -0.33 & Makanjuola et al. (2020) & -0.29 & Makanjuola et al. (2020) \\
\hline FSTC_C (d) & 0.19 & Makanjuola et al. (2020) & 0.16 & Makanjuola et al. (2020) \\
\hline Calving interval (d) & 0.48 & Doekes et al. (2019) & $0.18-0.7$ & Pryce et al. (2014) \\
\hline Ease of calving & 0.04 & Bjelland et al. (2013) & 0.06 & Rokouei et al. (2010) \\
\hline \multicolumn{5}{|c|}{ Conformation parameters for ease of calving } \\
\hline Rump angle & -0.14 & Bjelland et al. (2013) & 0.01 & Croquet et al. (2006) \\
\hline Rump width & -0.03 & Bjelland et al. (2013) & -0.33 & Croquet et al. (2006) \\
\hline
\end{tabular}

AFS_H: Age at first service for heifers, NS_H: Number of services for heifers, NRR_H: 56-day non-return rate for heifers, FSTC_H: First service to conception for heifers, CTFS_C: Conception to the first service for cows, NS_C: Number of service for cows, NRR_C: 56-d non-return rate for cows, FSTC_C: First service to conception for cows. Estimates were readjusted as standardized linear regression coefficients.

conventional traits regarding new traits included in genetic improvement programs in recent years.

\section{Effects of inbreeding depression on reproduction}

Increased inbreeding rates have been associated with reduced reproductive capacity in major dairy breeds (Martikainen et al., 2020). In the Holstein breed, it has been shown that classic, ancestral and future inbreeding has detrimental effects on fertility and survival traits (McParland et al., 2009). For decades, the analysis to determine the degree of inbreeding has been performed relying on genealogical data, and adverse effects on reproduction have been reported (Hermas et al., 1987). For example, pedigree-based estimations of the inbreeding coefficients in the Ayrshire breed show important differences derived from inbreeding depression on the fertility indexes, the prediction through genomic analysis being more precise (Martikainen et al., 2017). Moreover, studies using solely genealogical data show that the estimation of the inbreeding coefficient had no significant effects on traits such as birth weight and calving ease (McParland et al., 2007). In contrast, a study in adult Holstein cattle showed that inbreeding, assessed by pedigree data, affected the calving interval trait and detected an increased incidence of difficult calvings (Rokouei et al., 2010). Evaluations of inbreeding depression from genomic data have shown a more accurate and significant prediction of reproductive traits (Martikainen et al., 2018) such as decreased oocyte and embryo competition (Perez et al., 2017), fetal death (Hinrichs and Thaller, 2011), udder health traits and overall fertility rates (Doekes et al., 2019) as well as days open and calving ease (Bjelland et al., 2013).

Genomic regions have also been identified that harbor harmful recessive mutations associated with decreased calving rates (Fritz et al., 2013) and lethal recessive mutations associated with embryonic death (VanRaden and Miller, 2006). Hence, the effects of inbreeding rates on different reproductive traits should be considered in genetic improvement programs in dairy cattle (Martikainen et al., 2017). For such evaluation, genomic evaluation techniques should be prioritized due to their predictive capacity and greater precision. Although the results of inbreeding estimation using pedigree data are similar to those estimated by genomics for some reproductive traits, certainly genomic estimations are more efficient and accurate (Weller et al., 2017). Some authors even claim that there is now evidence of increased predictive accuracy using genomic analyses in dairy cattle breeds in this respect (Martikainen et al., 2018, 2020). Through genomic methods, the different regions in the genome that have been identified as harboring harmful recessive mutations associated with negative phenotypic effects involve calving rates (Fritz et al., 2013), embryonic death (VanRaden and Miller, 2006), fertility (Martikainen et al., 2017), calving interval, dystocic parturition (Rokouei et al., 2010; Bjelland et al., 2013), decreased oocyte/ embryo competence (Perez et al., 2017), early fetal death (Hinrichs and Thaller, 2011), lower fertility rates (Doekes et al., 2019), and increased open days (Bjelland et al., 2013). In contrast, other studies mention that inbreeding had no significant effect on specific traits such as birth weight and calving ease (McParland et al., 2009). We consider that the negative impact generated by inbreeding on most reproductive traits is evident. However, these effects would be presented in greater or lesser proportion to the levels of inbreeding present in each individual studied and directly proportional to the number of genomic regions harboring recessive mutations (Fritz et al., 2013) and lethal recessive mutations (VanRaden and Miller, 2006). These effects have been increasing simultaneously with the evolution of higher yields in 
dairy cattle (Cole et al., 2016). In this sense, from the genotyping of genomic regions affected by inbreeding, further studies are suggested to identify a more significant proportion of regions to propose strategies to reduce the effects of inbreeding and maintain a balance between production levels, reproduction and inbreeding coefficients.

\section{Influence of inbreeding depression in health and welfare}

Health indices are fundamental factors in dairy farming as they directly influence animal welfare. In recent years, genomic evaluations of dairy cattle have incorporated new traits related to animal welfare that had not previously been considered. These traits play a major role in the overall health of the individual. In that sense, several studies give importance to the effect of inbreeding depression on health and animal welfare traits associated with dairy cattle longevity (Baes et al., 2019).

An increment of the inbreeding coefficient is a serious factor that increases the risk of activation of harmful recessive genes potentially influencing the cattle's immune system (Macedo et al., 2014). Thus, increased inbreeding coefficients would be directly associated with the expression of recessive genes that impair the overall immune system, even affecting mitochondrial DNA (Macedo et al., 2014; Baes et al., 2019), udder health (Doekes et al., 2019), linear conformation traits, dairy temperament, survival, general health status, individual vigor and strength (Cassell et al., 2003). Doekes et al. (2019) also observed that inbreeding depression due to recent, compared to old inbreeding, significantly affected udder health. Health and animal welfare traits are strongly linked to the longevity of dairy cows, thereby increasing the time they remain in dairy operations, which impacts profitability. Therefore, these desirable health trait genotypes should be included in all dairy cattle evaluation, selection, and breeding systems to transmit them to future generations. We also emphasize that those dairy systems that maintain longevity traits in present populations will be highly profitable in the medium and long term.

\section{Consequences of inbreeding depression on linear conformation}

There is still some controversy regarding the impact of inbreeding on the conformation of dairy cows. The highly specialized conformation in high-yield dairy cattle has demanded the use of strongly related genetic lines initially derived from only about ten sires (Battagin et al., 2013). Several authors claim that in dairy breeds such as Holstein, the high levels of inbreeding brought about by the convergence of genetic lines negatively affect several traits including linear conformation (morphological lines) (Croquet et al., 2006; Rokouei et al., 2010; Battagin et al., 2013). These traits would be strongly associated with longevity, production, and reproductive capacity (Smith et al., 1998; Sewalem et al., 2006). The reason for this is because adaptability traits, including conformation, longevity, and even disease resistance traits, show low heritability and decrease as levels of milk production per cow increase over time (Mirkena et al., 2010). However, the importance of these characteristics derived from high inbreeding could be genotypically and phenotypically more related to longevity, production, and reproductive ability (Sewalem et al., 2006) than conformation. Another study showed that the degree of inbreeding had little effect on conformation traits but more adverse effects on production traits (Smith et al., 1998). However, several studies based on a genealogical analysis in
Holstein sires and dams regarding linear conformation traits showed that the degree of inbreeding significantly influences height, chest width, body depth, udder size and height, median suspensory ligament, udder depth, and teat placement (Rokouei et al., 2010).

\section{Repercussions of inbreeding depression on adaptability}

The adaptability of dairy cattle to different environments has been the result of century-old natural evolution. Therefore the real adaptability of cattle to different current production systems and new environments is debatable. For example, a study conducted in nine native Russian cattle breeds identifying candidate known genes and other new genes related to domestication and production traits such as milk production (e.g. DGAT1, $A B C G 2$ ), growth (e.g. XKR4), reproduction (e.g. CSF2) and environmental adaptation (e.g. AQP5, RAD50, RETREG1) showed highly variable results (Yurchenko et al., 2018). This way, during the last centuries, human beings have constantly been working out the specialization of dairy cattle to obtain a high-performance phenotype in the process of continuous matings of genetically related lineages with the accompanying increase in inbreeding rates (Refoyo-Martínez et al., 2019). Therefore, evaluating the individual inbreeding coefficient is crucial for the progress of animal adaptation, evolution, and conservation biology (Kardos et al., 2015). Consequently, the degree of endogamy generated and the specialization of dairy cattle reached so far could have a considerable influence on the capacity of adaptability of dairy cattle to new environments and different production systems, for which additional research is necessary.

The breeding success and the improved adaptability of dairy cattle to different environments is controversial as this trait has low heritability (Strandén et al., 2019). This natural evolutionary trait takes several centuries to become fixed in cattle (Åby and Meuwissen, 2014). Yet, the specialization of dairy breeds has led to an increase in inbreeding rates (Refoyo-Martínez et al., 2019), with variable heritability estimates observed regarding genes of domestication, production, reproduction, growth, and environmental adaptability (Yurchenko et al., 2018). The adequate and permanent monitoring of both individual and population inbreeding in dairy cattle is necessary to mitigate detrimental genetic effects related to cattle adaptability to different environments and production systems in the near future (Kardos et al., 2015).

Accordingly, the need for the adaptation of dairy cattle to imminently emerging environments is a current concern. A recent study compared selection strategies in dairy cattle correlating productive traits (moderately heritable) with adaptive traits (low heritability) using simulations (Strandén et al., 2019). This study concluded that genomic introgression (gene movements) produced more positive genetic change for both production and adaptive traits depending on the weight given to the adaptive or production traits during selection. Furthermore, this genomic introgression system seems to generate a lower risk of inbreeding. In general, results from simulations suggest that genomic selection can effectively introgress a low heritable trait into a target highproduction population when the traits, i.e. the introgressed trait and production, are polygenic and genetically non-correlated (Åby and Meuwissen, 2014; Gaspa et al., 2015). Therefore, in the face of constant environmental changes that characterize current times, it is essential to highlight that one solution would point to introducing local adaptive genes in the most important 
dairy breeds (Nardone et al., 2006; Hoffmann, 2010) (Berman, 2011; Hoffmann, 2013). This genetic input could be an efficient strategy to introduce adaptive traits into commercial breeds (Strandén et al., 2019; Hoffmann et al., 2021).

It is also important to remark that dairy cattle populations must be prepared for future adaptive scenarios arising from the ongoing climate change. Therefore, the adaptability of animal populations to future environments will be vital for the proper performance of dairy breeds, suggesting that both adaptive and production traits can be simultaneously improved through genomic introgression (Strandén et al., 2019). Therefore, introducing adaptive genes from donor dairy breed populations into less adapted recipient populations should be a central strategy. This introduction of genes would be a compelling way to increase genetic variability and avoid an increase in inbreeding depression and associated adverse effects on different genomic and phenotypic traits.

\section{Strategic priorities to control inbreeding depression}

Considering the increase in the annual loss of gene variability in studies involving Holstein sires (Doublet et al., 2019), recent work proposes that inbreeding should be controlled through evaluations based on genotyping because this control will be much more rigorous in genomic-based breeding programs than in those using pedigree for this purpose (Howard et al., 2017; Mäntysaari et al., 2020). Genomic selection has become an established approach and the standard in numerous dairy cattle production systems (Wiggans et al., 2017). Likewise, genomics has now paved the way for an extraordinary increase in genetic progress for most dairy cattle populations by drastically reducing the generation interval (Maltecca et al., 2020). Under genomic selection systems, an increase in the annual cumulative inbreeding rate has been observed due to the shortening of the generation interval through the use of genetic material from genetically related sires (Maltecca et al., 2020). This increase has favored the homozygosity effect to rapidly build up in dairy cattle populations (Howard et al., 2017). Therefore, a better understanding of how homozygosity and recessive load are related will ensure continuous genetic improvement, reduce the accumulation of harmful recessive genes and maintain genetic variability at the population level in dairy cattle (Maltecca et al., 2020). Regrettably, the accumulation of inbreeding depression is the unintended result of how selection has been performed in breeding programs over the past decades (Doekes et al., 2019). Thus, the inbreeding rate per generation could decrease, since genomic selection can be used in a larger pool of candidates as we are not restricted by the limitations of traditional progeny testing systems, which allows only the testing of fewer candidates (Daetwyler et al., 2007; Yurchenko et al., 2018). The degree of inbreeding is an imperfect measure of an individual's underlying recessive load because the accumulation of homozygosity for beneficial variants, compared to neutral or deleterious loci, cannot be distinguished (Gulisija and Crow, 2007). However, information derived from the current genomic analysis methods has identified 18 lethal recessive loci (Cole et al., 2016). Therefore, the possibility to identify such loci with high accuracy may prevent adverse phenotypic effects in future matings, avoiding high inbreeding rates by identifying partial dominance and partial recessives (Jiang et al., 2019).

Estimates of future inbreeding evaluated through pedigree are more subjective and show a greater degree of underestimation (Sell-Kubiak et al., 2018). However, the fact that genomic evaluation of inbreeding is more accurate than inbreeding levels obtained from pedigrees suggests that genomic inbreeding could better predict the actual recessive load to be taken into account in different dairy cattle breeding programs (Forutan et al., 2018). Therefore, it is essential to highlight the need for the association of genomic and pedigree data to improve the estimation in the prediction of the traits, allowing us to perform matings with open lines of sires and consequently decreasing the degree of inbreeding (Gutiérrez-Reinoso et al., 2020; VanRaden, 2020).

Several state-of-the-art methods, such as those based on highdensity single nucleotide polymorphisms (SNPs), are currently emerging as tools for identifying recessive lethal load, and therefore, for the selection of individuals carrying recessive genes (Cole et al., 2016; Maltecca et al., 2020) (Fig. 2). This fact could be considered a possible complementary tool to genome editing when variants are recessive (Cole, 2015). However, a better formulation of different models, including dominance, has recently been achieved. This approach makes dominance estimates free of harmful effects arising from inbreeding (Vitezica et al., 2017).

On dairy farms in different countries, including the USA, inbreeding control programs have been implemented at the population level using projections of expected future inbreeding or future genomic inbreeding (Sun et al., 2014). However, one of the most effective methods for managing long-term genetic variability and inbreeding is optimum contribution selection (OCS). This has been available since the 1990s, although the practical use of this tool has been minimal (Maltecca et al., 2020). Therefore, it is essential to consider which selection allocates the contributions of each potential parent to minimize the overall weighted co-ancestry between prospective parents weighted by their contributions (Meuwissen, 1997).

One of the most important advances obtained to date has been the implementation of several computer methods such as the genomic best linear unbiased predictor (BLUP) of a single step (ssGBLUP) to perform studies of genome-wide association (GWAS), genomic prediction and estimation of several traits, taking into account the inbreeding index (Strandén et al., 2017; Kang et al., 2018). It has also been shown that the use of genomic relationships for inbreeding control is more efficient when assessing very large families of full siblings as opposed to single individuals (Clark et al., 2013). Thus, runs of homozygosity (ROHs) have been proposed as a measure to track autozygosity and recent inbreeding that would be related to the actual recessive load of individuals (Clark et al., 2013; Doekes et al., 2019) (Fig. 2).

\section{Conclusions and future perspectives}

Although genome editing technologies facilitate efficient cattle breeding without introducing transgenes, it can be difficult for the public to understand their possible benefits. However, we are currently witnessing that the use of strategies to eliminate deleterious alleles by genome editing is becoming real in cattle breeding, and it promises to be very advantageous. Thus, genome editing could prove helpful in eliminating deleterious recessive alleles identified by bioinformatics screening methods, which use sequence conservation and prior biological information about protein function. Genomics as a tool to control the harmful effects of inbreeding depression will continue to be the methodology of reference in the coming years. It will be increasingly used as an efficient set of methods to control and restrict the accumulation of genome homozygosity in dairy cattle. Breeding programs aim to maintain genetic diversity and limit the buildup of inbreeding, thus maximizing the response to selection. This 


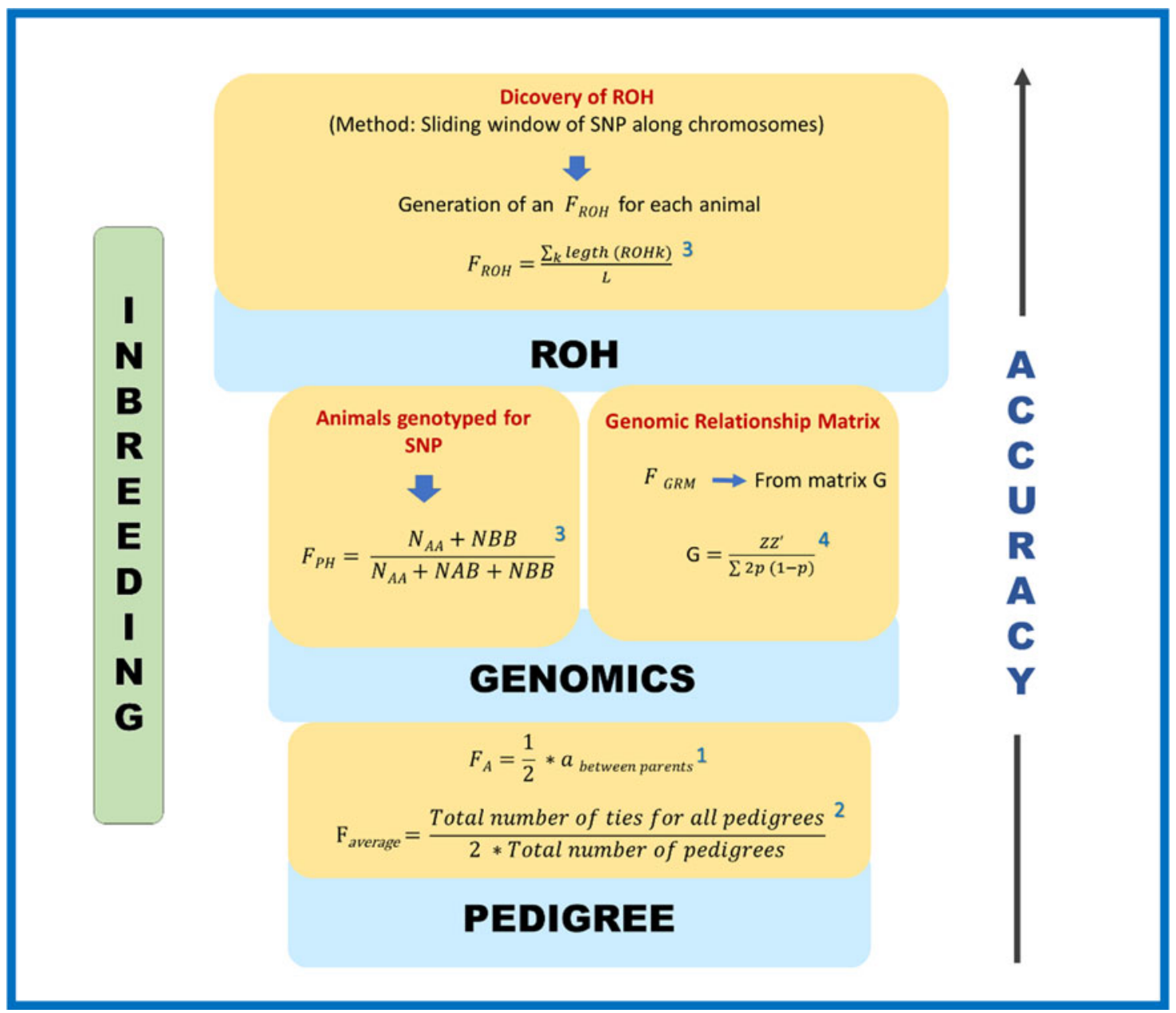

Fig. 2. Main methods for the determination of inbreeding. The inbreeding coefficient $(F)$ has been estimated from the pedigree of animals since around 100 years ago. $\mathrm{A}=$ animal = offspring; $\mathrm{a}=$ additive genetic relationship. $F A \rightarrow[0-1]$, is the probability for each locus of the offspring evaluated to be homozygous because their parents received the same alleles from a common ancestor (Oldenbroek and Waaij, 2014) ${ }^{1}$; (Young and Seykora, 1996) ${ }^{2}$. Genomic methods are based on SNPs (Single nucleotide polymorphisms) and provide higher accuracy to $\mathrm{F}$ estimation. Besides, the pedigree of animals does not need to be known. $F_{\mathrm{PH}}=$ percentage of homozygosity of all SNP. $N_{\mathrm{AA}}, N_{\mathrm{AB}}, N_{\mathrm{BB}}=$ number of SNP classified as AA, AB and BB, respectively. $F_{\mathrm{PH}}$ does not distinguish between IBD (Identical by Descent, which what we aim $F$ to be based on, represented by alleles descended from a common ancestor in a base population and IBS (identical by state, identical alleles regardless of whether they are inherited by a recent ancestor or not) (Bjelland et al., 2013) ${ }^{3} \mathrm{G}=$ matrix that contains allele frequencies, in rows $\rightarrow 0$ - $2 p$ (homozygotes); $1-2 p$ (heterozygotes); $2-2 p$ (opposite homozygotes). Columns correspond to each marker. $p=$ allele frequency (VanRaden et al., 2011) ${ }^{4}$. ROH = Runs of homozygosity. $F_{\mathrm{ROH}}$ can be estimated genomically. ROHs are a specific number of consecutive homozygous SNP. Inbreeding is characterized by high homozygosity and is highly clustered in the genome sequence space. Therefore, ROHs are long runs of homozygous SNP that become inherited together (Bjelland et al., 2013). $\mathrm{F}_{\mathrm{ROH}}$ is more accurate in the sense that it better detects IBD. $\mathrm{F}_{\mathrm{ROH}}$ is higher when ROHs are long, and this will be associated with a short distance to common ancestors in the pedigree line (chromatin will not have had time to fragment during meiosis through more generations as would happen when related animals are further back in the pedigree), (Bjelland et al., 2013) ${ }^{3} ; \sum_{k}$ length = number of ROH discoveries per animal; $L=$ Total genome length (in kilobases, Kb). References: (1) (Oldenbroek and Waaij, 2014) (2) (Young and Seykora, 1996) (3) (Bjelland et al., 2013) (4) (VanRaden et al., 2011).

goal can be achieved by maximizing the effective population size and minimizing the rate of inbreeding through control methods. With the adoption of genomics, the dairy genetics industry is slowly transforming and moving toward scenarios similar to those of other species in which control of population size is critical for inbreeding control in contrast to the information obtained from pedigree data. The combined use of data from pedigreebased relationships, genomics, OCS and $\mathrm{ROH}$, among other methods, will help to improve accuracy at identifying the different lethal recessive loci of full and partial dominance, as well as other loci affecting other full and partial recessive traits. Also, inbreeding more closely related to overall recessive load could be determined either through the use of $\mathrm{ROH}$ or age-related partial inbreeding coefficients. Although managing lethal mutations has become more effective in recent years, considerable economic losses are associated with partial recessive loci of small effect. The significant amount of information gathered in recent years, based on several million individuals genotyped, offers an excellent opportunity to investigate partial recessive load and functional inbreeding depression, thus discriminating homozygosity and its potentially detrimental effects. The identification of truly deleterious partial recessives remains a long-term challenge in dairy cattle. The preservation of genetic diversity in future generations of dairy cattle is necessary to maintain current and future production in different environments. The application of intense genetic improvement and genetic introgression will guarantee increases in the frequency of favorable additive alleles and gene migration between donor and recipient populations. All these pieces of 
evidence suggest that genomic evaluation can be a standard tool in programs of reproduction, selection, and genetic improvement of dairy cattle.

Acknowledgements. We would like to thank the people and laboratories involved in the research related to the present review topic. Authors would like to acknowledge the support of the Universidad San Francisco de Quito (USFQ), Ecuador; Universidad Técnica de Cotopaxi (UTC), Ecuador; Agencia Nacional de Investigación y Desarrollo (ANID); Programa de Becas/Doctorado Nacional/2020-21201280, Chile and the National Institute for Agricultural and Veterinary Research (INIAV), Portugal. The contents of this review are solely the responsibility of the authors and do not necessarily represent the official views of the above-mentioned institutions.

\section{References}

Åby B and Meuwissen T (2014) Proceedings, 10th World Congress of Genetics Applied to Livestock Production Selection strategies utilizing genetic resources to adapt livestock to climate change.

Baes C, Makanjuola B, Miglior F, Marras G, Howard J, Fleming A and Maltecca C (2019) Symposium review: the genomic architecture of inbreeding: how homozygosity affects health and performance. Journal of Dairy Science 102, 2807-2817.

Bailey R (2017) Christopher Polge and Lionel Edward Aston Rowson's Experiments on the Freezing of Bull Spermatozoa (1950-1952).

Battagin M, Sartori C, Biffani S, Penasa M and Cassandro M (2013) Genetic parameters for body condition score, locomotion, angularity, and production traits in Italian Holstein cattle. Journal of Dairy Science 96, 5344-5351.

Berman A (2011) Invited review: are adaptations present to support dairy cattle productivity in warm climates? Journal of Dairy Science 94, 2147-2158.

Bjelland D, Weigel K, Vukasinovic N and Nkrumah J (2013) Evaluation of inbreeding depression in Holstein cattle using whole-genome SNP markers and alternative measures of genomic inbreeding. Journal of Dairy Science 96, 4697-4706.

BovineSNP50 DNA Analysis Kit (2021) Retrieved May 16, from https://www. illumina.com/products/by-type/microarray-kits/bovine-snp50.html.

Cassell B, Adamec V and Pearson R (2003) Effect of incomplete pedigrees on estimates of inbreeding and inbreeding depression for days to first service and summit milk yield in Holsteins and Jerseys. Journal of Dairy Science 86, 2967-2976.

Clark S, Kinghorn B, Hickey J and Van Der Werf J (2013) The effect of genomic information on optimal contribution selection in livestock breeding programs. Genetics Selection Evolution 45, 44.

Cole J (2015) A simple strategy for managing many recessive disorders in a dairy cattle breeding program. Genetics Selection Evolution 47, 94.

Cole J, Null D and VanRaden P (2016) Phenotypic and genetic effects of recessive haplotypes on yield, longevity, and fertility. Journal of Dairy Science 99, 7274-7288.

Croquet C, Mayeres P, Gillo A, Vanderick S and Gengler N (2006) Inbreeding depression for global and partial economic indexes, production, type, and functional traits. Journal of Dairy Science 89, 2257-2267.

Croquet C, Mayeres P, Gillon A, Hammami H, Soyeurt H, Vanderick S and Gengler N (2007) Linear and curvilinear effects of inbreeding on production traits for walloon Holstein cows. Journal of Dairy Science 90, 465-471.

Daetwyler H, Villanueva B, Bijma P and Woolliams J (2007) Inbreeding in genome-wide selection. Journal of Animal Breeding and Genetics 124, 369-376.

Darwi C (1876) The Effects of Cross and Self Fertilisation in the Vegetable Kingdom. London: John Murray, Retrieved May 16, 2021.

Data Sheet: DNA Analysis (2021) Retrieved, from http://mathgen.stats.ox.ac. uk/impute/impute.

de Oliveira Seno L, Guidolin D, Aspilcueta-Borquis R, do Nascimento G, da Silva T, de Oliveira H and Munari D (2018) Genomic selection in dairy cattle simulated populations. Journal of Dairy Research 85, 125-132.

Dezetter C, Leclerc H, Mattalia S, Barbat A, Boichard D and Ducrocq V (2015) Inbreeding and crossbreeding parameters for production and fertility traits in Holstein, Montbéliarde, and Normande cows. Journal of Dairy Science 98, 4904-4913.

Doekes H, Veerkamp R, Bijma P, De Jong G, Hiemstra S and Windig J (2019) Inbreeding depression due to recent and ancient inbreeding in Dutch Holstein-Friesian dairy cattle. Genetics Selection Evolution 51, 51-54.

Doublet A, Croiseau P, Fritz S, Michenet A, Hozé C, Danchin-Burge C, Laloë D and Restoux G (2019) The impact of genomic selection on genetic diversity and genetic gain in three French dairy cattle breeds. Genetics Selection Evolution 51, 52.

Forutan M, Ansari Mahyari S, Baes C, Melzer N, Schenkel F and Sargolzaei M (2018) Inbreeding and runs of homozygosity before and after genomic selection in North American Holstein cattle. BMC Genomics 19, 98.

Fritz S, Capitan A, Djari A, Rodriguez S, Barbat A, Baur A, Grohs C, Weiss B, Boussaha M, Esquerré D, Klopp C, Rocha D and Boichard D (2013) Detection of haplotypes associated with prenatal death in dairy cattle and identification of deleterious mutations in GART, SHBG and SLC37A2. PLOS ONE 8, e65550.

Gandini G, Stella A, del Corvo M and Jansen G (2014) Selection with inbreeding control in simulated young bull schemes for local dairy cattle breeds. Journal of Dairy Science 97, 1790-1798.

Gaspa G, Veerkamp R, Calus M and Windig J (2015) Assessment of genomic selection for introgression of polledness into Holstein Friesian cattle by simulation. Livestock Science 179, 86-95.

Gulisija D and Crow J (2007) Inferring purging from pedigree data. Evolution 61, 1043-1051.

Gutiérrez-Reinoso M, Aponte P, Cabezas J, Rodriguez-Alvarez L and Garcia-Herreros M (2020) Genomic evaluation of primiparous highproducing dairy cows: inbreeding effects on genotypic and phenotypic production-reproductive traits. Animals 10, 1-18.

Gutierrez-Reinoso M, Aponte P and Garcia-Herreros M (2021) Genomic analysis, progress and future perspectives in dairy cattle selection: a review. Animals 11, 1-21.

Hayes B and Goddard M (2008) Technical note: prediction of breeding values using marker-derived relationship matrices. Journal of Animal Science 86, 2089-2092.

Hermas S, Young C and Rust J (1987) Effects of mild inbreeding on productive and reproductive performance of Guernsey cattle. Journal of Dairy Science 70, 712-715.

Hinrichs D and Thaller G (2011) Pedigree analysis and inbreeding effects on calving traits in large dairy herds in Germany. Journal of Dairy Science 94, $4726-4733$.

Hoffmann I (2010) Climate change and the characterization, breeding and conservation of animal genetic resources. Animal Genetics 41(Suppl. 1), 32-46.

Hoffmann I (2013) Adaptation to climate change - exploring the potential of locally adapted breeds. Animal: An International Journal of Animal Bioscience 7, 346-362.

Hoffmann A, Miller A and Weeks A (2021) Genetic mixing for population management: from genetic rescue to provenancing. Evolutionary Applications 14, 634-652.

Howard J, Pryce J, Baes C and Maltecca C (2017) Invited review: inbreeding in the genomics era: inbreeding, inbreeding depression, and management of genomic variability. Journal of Dairy Science 100, 6009-6024.

Jiang J, Ma L, Prakapenka D, VanRaden P, Cole J and Da Y (2019) A large-scale genome-wide association study in U.S. Holstein cattle. Frontiers in Genetics 10, 412.

Kang H, Ning C, Zhou L, Zhang S, Yan Q and Liu J (2018) Short communication: single-step genomic evaluation of milk production traits using multiple-trait random regression model in Chinese Holsteins. Journal of Dairy Science 101, 11143-11149.

Kardos M, Luikart G and Allendorf F (2015) Measuring individual inbreeding in the age of genomics: marker-based measures are better than pedigrees. Heredity 115, 63-72.

Keller M, Visscher P and Goddard M (2011) Quantification of inbreeding due to distant ancestors and its detection using dense single nucleotide polymorphism data. Genetics 189, 237-249.

Leibo S, Semple M and Kroetsch T (1994) In vitro fertilization of oocytes by 37-year-old cryopreserved bovine spermatozoa. Theriogenology 42, 12571262. 
Leroy G (2014) Inbreeding depression in livestock species: review and meta-analysis. Animal Genetics 45, 618-628.

Ma L, Cole J, Da Y and VanRaden P (2019) Symposium review: genetics, genome-wide association study, and genetic improvement of dairy fertility traits. Journal of Dairy Science 102, 3735-3743.

Macedo A, Bittar J, Bass P, Ronda J, Bittar E, Panetto J, Araujo M, Santos R and Martins-Filho $\mathbf{O}$ (2014) Influence of endogamy and mitochondrial DNA on immunological parameters in cattle. BMC Veterinary Research 10, 79.

Makanjuola B, Maltecca C, Miglior F, Schenkel F and Baes C (2020) Effect of recent and ancient inbreeding on production and fertility traits in Canadian Holsteins. BMC Genomics 21, 605.

Maltecca C, Tiezzi F, Cole J and Baes C (2020) Symposium review: exploiting homozygosity in the era of genomics - selection, inbreeding, and mating programs. Journal of Dairy Science 103, 5302-5313.

Mäntysaari E, Koivula M and Strandén I (2020) Symposium review: singlestep genomic evaluations in dairy cattle. Journal of Dairy Science 103, 53145326.

Martikainen K, Tyrisevä A, Matilainen K, Pösö J and Uimari P (2017) Estimation of inbreeding depression on female fertility in the Finnish Ayrshire population. Journal of Animal Breeding and Genetics 134, 383-392.

Martikainen K, Sironen A and Uimari P (2018) Estimation of intrachromosomal inbreeding depression on female fertility using runs of homozygosity in Finnish Ayrshire cattle. Journal of Dairy Science 101, 11097-11107.

Martikainen K, Koivula M and Uimari P (2020) Identification of runs of homozygosity affecting female fertility and milk production traits in Finnish Ayrshire cattle. Scientific Reports 10, 3804.

McParland S, Kearney J, Rath M and Berry D (2007) Inbreeding effects on milk production, calving performance, fertility, and conformation in Irish Holstein-Friesians. Journal of Dairy Science 90, 4411-4419.

McParland S, Kearney F and Berry D (2009) Purging of inbreeding depression within the Irish Holstein-Friesian population. Genetics Selection Evolution 41, 41-16.

Meuwissen T (1997) Maximizing the response of selection with a predefined rate of inbreeding. Journal of Animal Science 75, 934-940.

Miglior F, Burnside E and Dekkers J (1995) Non-additive genetic effects and inbreeding depression for somatic cell counts of Holstein cattle. Journal of Dairy Science 78, 1168-1173.

Miglior F, Van Doormaal B, Kistemaker G, Canada A, Network C and Swiss B (2001) Phenotypic analysis of inbreeding depression for traits measured in Canadian dairy cattle breeds. Canadian Dairy Network 1967, 1-16.

Mirkena T, Duguma G, Haile A, Tibbo M, Okeyo A, Wurzinger $M$ and Sölkner J (2010) Genetics of adaptation in domestic farm animals: a review. Livestock Science 132, 1-12.

Nardone A, Ronchi B, Lacetera N and Bernabucci U (2006) Climatic effects on productive traits in livestock. Veterinary Research Communications 30, 75-81.

Oldenbroek K and Waaij L (2014) Textbook animal breeding: animal breeding and genetics for BSc students.

Perez B, Balieiro J, Ventura R, Bruneli F and Peixoto M (2017) Inbreeding effects on in vitro embryo production traits in Guzerá cattle. Animal: An International Journal of Animal Bioscience 11, 1-8.

Polge C and Rowson L (1952) Fertilizing capacity of bull spermatozoa after freezing at $-79^{\circ} \mathrm{C}$. Nature $169,626-627$.

Possingham HP, McCarthy $\mathbf{M}$ and Lindenmayer D (2013) Population viability analysis. In Levin SA (ed) Encyclopedia of Biodiversity. 2nd Edn. Amsterdam, The Netherlands, pp. 210-219.

Pryce J, Haile-Mariam M, Goddard M and Hayes B (2014) Identification of genomic regions associated with inbreeding depression in Holstein and Jersey dairy cattle. Genetics Selection Evolution 46, 1-14.

Refoyo-Martínez A, da Fonseca R, Halldórsdóttir K, Árnason E, Mailund T and Racimo F (2019) Identifying loci under positive selection in complex population histories. Genome Research 29, 1506-1520.
Rokouei M, Vaez Torshizi R, Moradi Shahrbabak M, Sargolzaei M and Sørensen A (2010) Monitoring inbreeding trends and inbreeding depression for economically important traits of Holstein cattle in Iran. Journal of Dairy Science 93, 3294-3302.

Sell-Kubiak E, Czarniecki $\mathbf{L}$ and Strabel T (2018) Challenges in inbreeding estimation of large populations based on Polish Holstein-Friesian cattle pedigree. Journal of Applied Genetics 59, 313-323.

Sewalem A, Kistemaker G, Miglior F and van Doormaal B (2006) Analysis of inbreeding and its relationship with functional longevity in Canadian dairy cattle. Journal of Dairy Science 89, 2210-2216.

Smith L, Cassell B and Pearson R (1998) The effects of inbreeding on the lifetime performance of dairy cattle. Journal of Dairy Science 81(10), 2729-2737.

Sonesson A, Woolliams J and Meuwissen T (2012) Genomic selection requires genomic control of inbreeding. Genetics Selection Evolution 44, 27.

Strandén I, Matilainen K, Aamand GP and Mäntysaari E (2017) Solving efficiently large single-step genomic best linear unbiased prediction models. Journal of Animal Breeding and Genetics 134, 264-274.

Strandén I, Kantanen J, Russo I, Orozco-terWengel $P$ and Bruford $M$ (2019) Genomic selection strategies for breeding adaptation and production in dairy cattle under climate change. Heredity 123, 307-317.

Sun C, VanRaden P, Cole J and O'Connell J (2014) Improvement of prediction ability for genomic selection of dairy cattle by including dominance effects. PLoS ONE 9, e103934.

Theunissen B (2008) Breeding without Mendelism: theory and practice of dairy cattle breeding in the Netherlands 1900-1950. Journal of the History of Biology 41, 637-676.

Thompson J, Everett R and Wolfe W (2000) Effects of inbreeding on production and survival in Jerseys. Journal of Dairy Science 83, 2131-2138.

VanRaden P (1992) Accounting for inbreeding and crossbreeding in genetic evaluation of large populations. Journal of Dairy Science 75, 3136-3144.

VanRaden P (2020) Symposium review: how to implement genomic selection. Journal of Dairy Science 103, 5291-5301.

VanRaden P and Miller R (2006) Effects of non-additive genetic interactions, inbreeding, and recessive defects on embryo and fetal loss by seventy days. Journal of Dairy Science 89, 2716-2721.

VanRaden P, Olson K, Wiggan G, Cole J and Tooker M (2011) Genomic inbreeding and relationships among Holsteins, Jerseys, and Brown Swiss. Journal of Dairy Science 94, 5673-5682.

Vitezica Z, Legarra A, Toro M and Varona L (2017) Orthogonal estimates of variances for additive, dominance, and epistatic effects in populations. Genetics 206, 1297-1307.

Weigel K and Lin S (2000) Use of computerized mate selection programs to control inbreeding of Holstein and Jersey cattle in the next generation. Journal of Dairy Science 83, 822-828.

Weller J, Ezra E and Ron M (2017) Invited review: a perspective on the future of genomic selection in dairy cattle. Journal of Dairy Science 100, 86338644.

Wiggans G, Cole J, Hubbard S and Sonstegard T (2017) Genomic selection in dairy cattle: the USDA experience. Annual Review of Animal Biosciences 5, 309-327.

Wright S and McPhee H (1925) An Approximate Method of Calculating Coefficients of Inbreeding and Relationship from Livestock Pedigrees.

Young C (1984) Inbreeding and the gene pool. Journal of Dairy Science 67, 472-477.

Young C and Seykora A (1996) Estimates of inbreeding and relationship among registered Holstein females in the United States. Journal of Dairy Science 79, 502-505.

Yurchenko A, Daetwyler H, Yudin N, Schnabel R, vander Jagt C, Soloshenko V, Lhasaranov B, Popov R, Taylor J and Larkin D (2018) Scans for signatures of selection in Russian cattle breed genomes reveal new candidate genes for environmental adaptation and acclimation Scientific Reports 8, 1-16. 